\title{
Fingernail May Not Be a Reliable Biomarker of Fluoride Body Burden from Dentifrice
}

\author{
Ynara Bosco Oliveira LIMA-ARSATI ${ }^{1}$ \\ Carolina Castro MARTINS ${ }^{2}$ \\ Lília Alves ROCHA ${ }^{3}$ \\ Jaime Aparecido CURY ${ }^{3}$ \\ ${ }^{1}$ São Leopoldo Mandic School of Dentistry and Research Center, Campinas, SP, Brazil \\ ${ }^{2}$ Federal University of Minas Gerais, Belo Horizonte, MG, Brazil \\ ${ }^{3}$ Piracicaba Dental School, University of Campinas, Piracicaba, SP, Brazil
}

\begin{abstract}
Fingernail has been suggested as a biomarker of fluoride (F) body burden, but there is no consensus if it would be a reliable indicator of $\mathrm{F}$ exposure from dentifrice. Therefore, the present study was conducted to investigate if fingernails would have sensitivity to detect $\mathrm{F}$ exposure from dentifrice in young children. Twenty-three 1-3-year-old children living in the city of Piracicaba $(0.72 \mathrm{ppm} F$ in water $)$, Brazil, were enrolled in two phases of different $F$ exposure: in phase A ( $1^{\text {st }}$ to $11^{\text {th }}$ week), they were exposed to the combination of $F$ from diet (solids and liquids) and dentifrice (1,500 $\mu \mathrm{g} \mathrm{F} / \mathrm{g}$ as MFP), and in phase B (12 th $29^{\text {th }}$ week), only to F from diet (the use of $\mathrm{F}$ dentifrice was interrupted). Fingernails were weekly clipped during 35 weeks for F determination. F intake from diet and dentifrice in each phase was also determined. Both analyses were made with ion-specific electrode. F intake (Mean \pm SD) was significantly higher $(\mathrm{p}<0.01)$ when the children were exposed to $\mathrm{F}$ from diet + dentifrice than only to $\mathrm{F}$ from diet $(0.086 \pm 0.032$ and $0.040 \pm 0.009$ $\mathrm{mg} \mathrm{F} /$ day/kg body weight, respectively). However, F concentrations in nails collected during the whole experimental period of 35 weeks presented great variation with no trend of decreasing after F dentifrice intake interruption. The findings suggest that fingernail may not be a reliable F biomarker of body burden from dentifrice.
\end{abstract}

Key Words: fluoride, water, fluoridation, dentifrice, fingernail, biomarkers, fluorosis.

\section{INTRODUCTION}

Due to the increase in the prevalence of dental fluorosis occurred in developed (1) and developing countries (2), irrespective of the exposure to fluoridated water (3), the search for biomarkers to monitor the several sources of body burden has incremented (4). Among the sources of fluoride $(\mathrm{F})$, drinking water and dentifrice are considered risk factors of fluorosis (5), but the real contribution of each source for fluorosis development is not clear and, in fact, a dose-response effect has not yet been established (6).

The use of nails as potential biomarkers of $\mathrm{F}$ body burden has been questioned (4). However, promising findings have been found when children living in communities with 1.6 or $2.3 \mathrm{ppm} \mathrm{F}$ in drinking water were shown to present significantly higher $\mathrm{F}$ concentrations in fingernails than populations living in communities with non-fluoridated water (7). Although the authors have reported that $\mathrm{F}$ concentration in fingernails from $2.3 \mathrm{ppm} \mathrm{F}$ area was significantly higher than the $1.6 \mathrm{ppm}$ $\mathrm{F}$ area, the $95 \%$ confidence interval showed an overlap between the values pointing that fingernails would not have sensitivity as a biomarker to differentiate small doses of $\mathrm{F}$ exposure.

In fact, conflicting findings has been found regarding nails as a biomarker for $\mathrm{F}$ intake. Rodrigues et al. (8) found a small but significant increase of $F$ concentration in nails of children during the period that they used $\mathrm{F}$ dentifrice in comparison with the period that they used a non-F dentifrice. However, such increase was not found in all children and fluctuations were observed over time. In another study, using the same protocol, fingernails did not have sensitivity to detect $F$ exposure from dentifrice or $\mathrm{F}$ varnish (9). No significant increase of $\mathrm{F}$ concentration in fingernails was observed in adults who ingested $1.8 \mathrm{mg} \mathrm{F}$ for 30 days either, but surprisingly the authors concluded that fingernails could

Correspondence: Prof. Dr. Jaime A. Cury, Av. Limeira 901, 13414-903 Piracicaba, SP, Brazil. Phone: + 55-19-2106-5303. Fax: + 55-19-2106-5302 e-mail: jcury@fop.unicamp.br 
be considered a biomarker for $\mathrm{F}$ based on two nails clippings that were within the $95 \%$ confidence interval calculated (10). Furthermore, when F intake from diet and dentifrice was evaluated in young children, there was no association between $\mathrm{F}$ concentration in fingernails and $\mathrm{F}$ intake (11).

Based on the lack of scientific evidence about the use of fingernails as a biomarker of $\mathrm{F}$ body burden, the present study was conducted to investigate if fingernails would have sensitivity to detect $F$ exposure from dentifrice in young children.

\section{MATERIAL AND METHODS}

\section{Ethical Aspects}

This study was approved by the Research Ethics Committee of the Piracicaba Dental School, University of Campinas, Brazil. Parents were informed about the research and agreed with their children participation by signing informed consent forms. Aiming to compensate for the non-use of $\mathrm{F}$ dentifrice during one phase of the study (phase B), the volunteers were subjected to the application of $1 \%$ chlorhexidine varnish (Cervitec; Vivacare, Schaan, Liechtenstein) on children's occlusal molar surfaces.

\section{Determination of the Growth Rate of Fingernails}

To estimate the time necessary for fingernail formation under determined $\mathrm{F}$ exposure, the time for nail growth from the matrix to the fingertip was determined in a pilot study. The fingernails of three children aged from 1 to 3 years old, from the daycare center from Piracicaba Dental School, were clipped at fingertip and the length of each fingernail's ungula bed was determined using a digital calipter $( \pm 0.01 \mathrm{~mm}$ ) (Mitutoyo Sul Americana Ltda., Suzano, SP, Brazil). The fingernails were clipped at fingertip three times, with intervals of 10 days, and the length of each piece of nail was measured in millimeters. After 30 days, the mean \pm SD growth rate was determined $(0.10 \pm 0.02 \mathrm{~mm} /$ day $)$ and the mean \pm SD time necessary for fingernail renewal was $8.3 \pm 1.6$ weeks), being the shortest period for minimum finger ( $7.2 \pm 1.8$ weeks) and the largest period for thumbnail ( $9.8 \pm 1.3$ weeks) in agreement with data from Irish children (12). Considering the extreme values of 7.2 and 9.8 weeks, it was stated that up to 7 weeks none fingernail was completely renewed but after 10 weeks all of them were. Thus, the interval between 8 and 9 weeks should be considered as a transitory period. Based on these data it was possible to separate the results of $\mathrm{F}$ concentration in nails formed under exposure to diet+dentifrice or only to diet as illustrated in Figure 1.

\section{Study Population}

A convenience sample of 23 1-3-year-old children (13 females and 10 males; mean age of $27.7 \pm 5.5$ months; mean body weight of $13.1 \pm 1.6 \mathrm{~kg}$ ) was selected at a daycare center located in a city with optimally fluoridated water (Piracicaba, SP, Brazil, 0.72 ppm F in

Experimental period: 35 weeks

\begin{tabular}{c|c}
\hline Phase A (1st to 11th weeks): & \\
F exposure from DIET + & Phase B (12th to 29th weeks): \\
DENTIFRICE & F exposure from DIET \\
Duplicate plate and & Duplicate plate collection for F \\
toothbrushing products & analysis \\
collection for F analysis &
\end{tabular}

Weekly fingernails collection for $F$ analysis

(Considering that the fingernails took 7.20 to 9.81 weeks to grow from matrix to fingertip)

\begin{tabular}{|c|c|c|c|}
\hline $\begin{array}{c}\text { 1st to 10th weeks: } \\
\text { Formed under undefined F } \\
\text { exposure }\end{array}$ & $\begin{array}{c}\text { 11th to 18th weeks: } \\
\text { Formed under F exposure from } \\
\text { DIET+DENTIFRICE }\end{array}$ & $\begin{array}{c}\text { 19th to 21st weeks: } \\
\text { Transition }\end{array}$ & $\begin{array}{c}\text { 22nd to 35th weeks: } \\
\text { Formed under F } \\
\text { exposure from DIET }\end{array}$ \\
\hline
\end{tabular}

Figure 1. Illustration of the experimental design. 
water). Only children who regularly consumed public water took part in the study.

\section{Experimental Design}

This prospective study comprised 35 consecutive weeks (Fig. 1). From $1^{\text {st }}$ to $11^{\text {th }}$ week (phase A), the children were exposed to $\mathrm{F}$ from their usual diet (solids and liquids) and received $\mathrm{F}$ dentifrice (Sorriso Dentes Brancos; Colgate-Palmolive Indústria e Comércio Ltda, São Bernardo dos Campos, SP, Brazil; 1,500 $\mu \mathrm{g} \mathrm{F/g}$ as MFP), which was used at the daycare center and at home. From the $12^{\text {th }}$ to $29^{\text {th }}$ week (phase B), the children used a non-F dentifrice formulated for this study (3.86 $\pm 1.45 \mu \mathrm{g} \mathrm{F} / \mathrm{g}$ ) at the daycare center and at home and were only exposed to $\mathrm{F}$ from diet (solids and liquids). In the $30^{\text {th }}$ week, for ethical reasons, children returned to use their usual dentifrice.

$F$ intake from diet and dentifrices was determined in the phases A and B. F intake from diet was determined in two non-consecutive days for each child and $\mathrm{F}$ intake from $\mathrm{F}$ dentifrice was determined twice (one toothbrushing supervised by the parent and one by the teacher).

Fingernails were collected from the $1^{\text {st }}$ to $29^{\text {th }}$ week and on the $35^{\text {th }}$ week. The nails were not collected from the $30^{\text {th }}$ to $34^{\text {th }}$ weeks due to daycare center vacation time. F concentration was determined in fingernails collected during all the period. However, to compare the values of $\mathrm{F}$ concentration of fingernails formed under exposure to diet+dentifrice (during phase A) or to diet (phase B), only the F concentration in fingernails collected, respectively, from the $11^{\text {th }}$ to $18^{\text {th }}$ weeks and from the $22^{\text {nd }}$ to $35^{\text {th }}$ weeks were considered. For each child, the week values of $\mathrm{F}$ concentration in fingernails collected during each specified period was averaged for the statistical analysis. The exclusion of the other samples collected was based on the interval of 7.2 to 9.8 weeks for fingernails renewal, as previously described.

\section{Fluoride Intake from Diet}

$F$ intake from diet was determined using the duplicate-plate collection method (13). Parents were instructed about the importance of maintaining the usual dietary patterns, and duplicating the diet as accurately as possible by observation of what the child actually ate and drank. Instructions were given to parents for the collections at home; at the daycare center collections were made by the researcher. Duplicate amounts of all foods and beverages ingested by the children were collected. Parts of foods not normally eaten, such as seeds, cores, skin and bones, were removed. Household measures, such as teaspoon and cupful, were used to approximate amounts of ingested food. Two similar portions of each meal were prepared onto two separate plates. After the child finished eating the meal on one of the plates, portions of food comparable to the food remaining on that plate were removed from the duplicate plate. The food that then remained on the duplicate plate was similar to the food eaten by the child. Beverages were duplicated in a similar manner. All foods and beverages collected during a whole day ( $24 \mathrm{~h})$ were gathered, taken to the laboratory and homogenized in a blender as one sample. The volume of each processed sample was recorded and an aliquot was stored in plastic cases at $-18^{\circ} \mathrm{C}$ until its analysis. For each phase, the duplicated plate collection was obtained for two non-consecutive days. Both the families and the daycare center were reimbursed for their costs with the duplicate-plate collection.

Analysis of $\mathrm{F}$ content from diet was conducted in triplicate. F concentration in each sample $(\mu \mathrm{g} \mathrm{F} / \mathrm{mL})$ was multiplied by the total volume of diet collected in one day. The calibration curve was analyzed in the same conditions as the diet samples and the quantity of $F$ found in blanks (distilled-deionized water) was subtracted from the value found in the samples.

\section{Fluoride Intake from Dentifrice}

F intake from dentifrice was monitored by maintaining the real conditions at home and at the daycare center. Children's toothbrushing was performed with the assistance of the parent or teacher, and under the supervision of the researcher. The toothbrush was weighed, dentifrice (Sorriso Dentes Brancos, Colgate-Palmolive Indústria e Comércio Ltda.; 1,500 $\mu \mathrm{g} \mathrm{F/g} \mathrm{as} \mathrm{MFP} \mathrm{and}$ calcium carbonate base, in which $981.8 \pm 39.8 \mu \mathrm{g} \mathrm{F} / \mathrm{g}$ was soluble) was squeezed onto the brush by the parent or teacher, and the brush with dentifrice was weighed again. Then, brush's weight was then subtracted from this value to determine the amount of dentifrice used $( \pm 0.01 \mathrm{~g})$. All expectorated saliva and deionized water used to rinse the mouth and the toothbrush after brushing were collected in a plastic cup. The volume was recorded and an aliquot of this slurry was frozen for subsequent $\mathrm{F}$ analysis. This procedure was carried out in order to determine the amount of $\mathrm{F}$ expectorated and not swallowed. $F$ ingested was determined subtracting the amount 
of $\mathrm{F}$ recovered in the slurry from the amount initially brushed their teeth at home and at the daycare center was evaluated, and this daily toothbrushing frequency was used to calculate the daily $\mathrm{F}$ intake from dentifrice for each child. Children were weighted to calculate $\mathrm{F}$ intake that was expressed in $\mathrm{mg} \mathrm{F} / \mathrm{kg}$ body weight/day.

\section{Fluoride Concentration in Fingernails}

Fingernails were cleaned with soap (Ultramet Sonic Cleaning Solution; Buehler, Lake Bluff, IL, USA), washed with distilled-deionized water, cut in small pieces and dried separately in an oven at $60^{\circ} \mathrm{C}$ for $2 \mathrm{~h}$. Fingernail clippings weighing up to $15 \mathrm{mg}$ were analyzed once (one sample), while those with more than $15 \mathrm{mg}$ were divided into two samples (duplicate). F content in each sample ( $\mu \mathrm{g} \mathrm{F}$ ) was divided by the weight of the nail analyzed $(\mathrm{g})$ to calculate $\mathrm{F}$ concentration $(\mu \mathrm{g} F / \mathrm{g})$.

\section{Fluoride Analysis}

F concentration in diet was determined by the hexamethyldisiloxane (HMDS)-facilitated diffusion technique (14), using a ion-specific F electrode (Orion placed onto the toothbrush. The frequency that children

Model 96-09, Orion Research Incorporated, Cambridge, MA, USA) and an ion analyzer (Orion Model EA 940, Orion Research Incorporated), previously calibrated with standards solutions (0.4-6.4 $\mu \mathrm{g} \mathrm{F} / \mathrm{mL})$ in triplicate, prepared in the same conditions of the samples.

For fingernail clippings, the diffusion technique (14) as modified by Whitford (15) was employed, using an ion-specific F electrode (Orion 9409) and a mini reference electrode (model 13-620-79; Accumet; Fisher Scientific, Tustin, CA, USA), coupled to an ion analyzer (Thermo Orion 720A; Orion Research Incorporated), previously calibrated with standard solutions (0.25-5.0 $\mathrm{nmol} \mathrm{NaF}$ ). The calibration and concentrations determined were tested in the linear regression curve, using Excel software, where a calculation program transformed the values of $\mathrm{mV}$ provided by the electrode in $\mu \mathrm{g} \mathrm{F} / \mathrm{mL}$ for each water sample and in $\mu \mathrm{g} \mathrm{F} / \mathrm{g}$ for each fingernail sample. The analyses were validated using internal standards and a coefficient variation lower than $5 \%$ was considered as acceptable.

Total soluble fluoride (TSF) concentration in the products collected during toothbrushing and in the dentifrices used by the children was determined by the direct method using an ion-specific electrode, after centrifugation, hydrolysis with $\mathrm{HCl} \mathrm{M}$ at $45^{\circ} \mathrm{C}$ and buffering with $\mathrm{NaOH} \mathrm{M}$ and TISAB II. The samples were analyzed in duplicate.

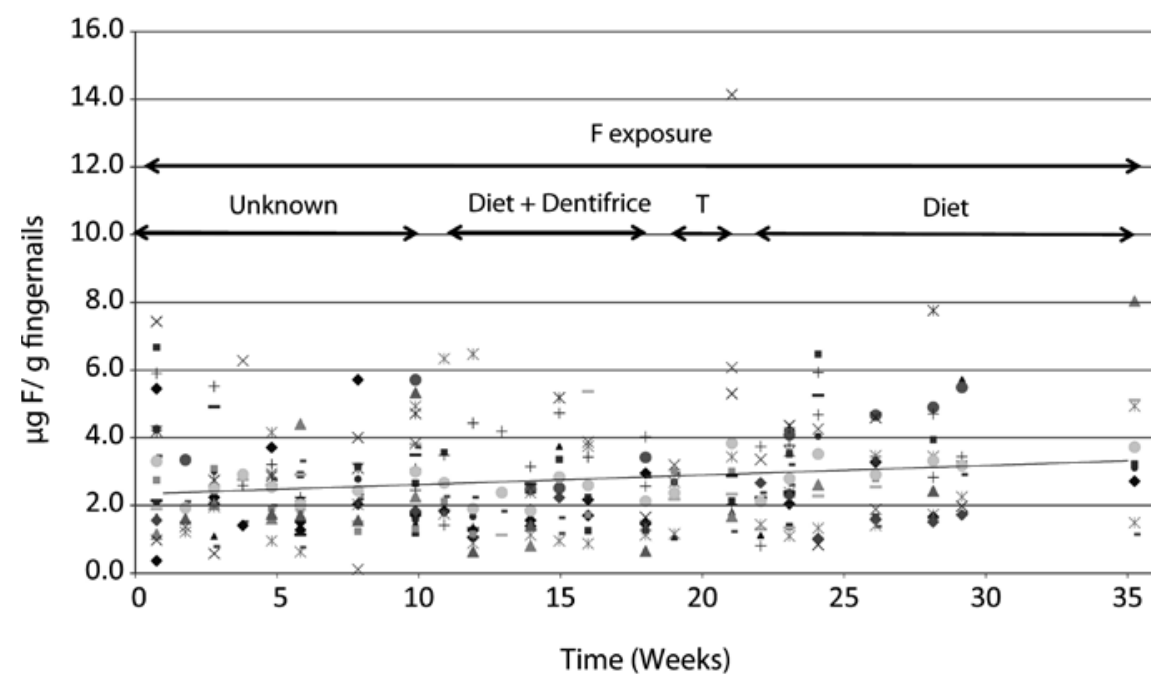

Figure 2. Fluctuations of $\mathrm{F}$ concentration in fingernails ( $\mu \mathrm{g} \mathrm{F/g}$ ) of the volunteers during the whole study (weeks). The line shows the trend of means week values during the period. The source of $F$ exposure from nails collected during the $1 \mathrm{st}$ to 10 th week was unknown, those collected during the 11th and 18th weeks were formed under exposure to $\mathrm{F}$ from diet+dentifrice, those during the 19th to 21 th weeks had part formed from diet + dentifrice and part only from diet (named transition $=\mathrm{T}$ ) and those from the 22 th and 35 th were formed only under exposure to diet.

\section{Statistical Analysis}

Data of $F$ in fingernails during the whole evaluation period were shown graphically and those from nails formed under diet + dentifrice (phase A) and only diet (phase B) were compared by paired $t$ test. The data of the F dose to which the children were subjected by diet+dentifrice and only by diet were also compared by the $t$ test. The association between $\mathrm{F}$ doses and concentration in the fingernails were estimated by Pearson's correlation as the data presented normal distribution. The BioEstat 2.0 soft- 
ware was used and the significance level was set at $5 \%$.

\section{RESULTS}

The $\mathrm{F}$ concentrations in fingernails along the 35 week-period are illustrated in Figure 2, and the data of $\mathrm{F}$ dose and $\mathrm{F}$ in fingernails formed during phases A (diet+dentifrice) and B (diet) are shown in Table 1.

The children were exposed to higher $F$ dose in the phase $\mathrm{A}$ (diet + dentifrice) than in the phase $\mathrm{B}(\mathrm{p}<$ 0.01 ), when the use of F-dentifrice was stopped (Table 1). However, $F$ concentration in fingernails formed during phase $\mathrm{B}$ was not lower than those formed during phase $A(p=0.049)$. Additionally, the correlations between $\mathrm{F}$ concentration in fingernails and total $\mathrm{F}$ dose (diet + dentifrice $)(p=0.165)$ or between $F$ concentration in fingernails and $\mathrm{F}$ dose from diet $(\mathrm{p}=0.701)$ were not statistically significant.

\section{DISCUSSION}

Fingernails have been suggested as a biomarker of $\mathrm{F}$ exposure and dentifrice has been considered a risk factor for dental fluorosis. However, data available in the literature are conflicting about their use to estimate the effect of $\mathrm{F}$ intake during toothbrushing (8-11).

The lack of consensus about this subject lies first on nail sensitivity as a biomarker to detect small difference of doses (mg F/day/kg body weight) to which children are subjected from any F source, and second,

Table 1. Mean \pm SD and (95\% confidence interval) of F dose ( $\mathrm{mg}$ $\mathrm{F} / \mathrm{kg}$ body weight/day) to which children were exposed in phase A (diet +dentifrice) and in phase B (diet), and F concentration in fingernails $\left(\mu \mathrm{g} \mathrm{F} / \mathrm{g}\right.$ ) formed during these respective phases ${ }^{\alpha}$ $(\mathrm{n}=23)$.

\begin{tabular}{lcc}
\hline $\begin{array}{l}\text { Phase }(\mathrm{F} \\
\text { exposure })\end{array}$ & $\begin{array}{c}\text { F dose } \\
(\mathrm{mg} \mathrm{F} / \mathrm{kg} \text { body } \\
\text { weight/day) }\end{array}$ & $\begin{array}{c}{[\mathrm{F}] \text { in fingernails }} \\
(\mu \mathrm{g} \mathrm{F} / \mathrm{g})\end{array}$ \\
\hline $\begin{array}{l}\text { A (Diet }+ \\
\text { Dentifrice) }\end{array}$ & $0.086 \pm 0.032$ & $2.57 \pm 1.49$ \\
& $(0.072-0.098)$ & $(1.96-3.18)$ \\
B (Diet) & $0.040 \pm 0.009$ & $3.33 \pm 1.41$ \\
p value $^{\beta}$ & $(0.036-0.043)$ & $(2.76-3.91)$ \\
\hline
\end{tabular}

${ }^{\alpha}$ Fingernails were collected from the 11 th to the 18 th weeks and from the 22 nd to the 35 th weeks during phases A and B, respectively (Fig. 1). ${ }^{\beta}$ Paired $t$ test between mean values within columns. when this source is a dentifrice, on the discrepancy between the dose of intake and the actual dose responsible for any systemic effect. Regarding the sensitivity of fingernails, there appear to be no studies showing doseresponse effect between $F$ ingested and its concentration in nails. Furthermore, the data in the literature regarding the $\mathrm{F}$ dose that children are systemically subjected are not accurate because they are based on the frequency of toothbrushing reported by the mothers, and on the total $F$ concentration in the dentifrice and not the bioavailable concentration (16). In addition, they do not consider that the amount of $\mathrm{F}$ absorbed depends on how long after meals the children taken to brush their teeth (17) and the meals eaten (18).

The present study showed that fingernails do not have sensitivity to detect the effect of $F$ ingestion from dentifrice to be used as a biomarker of fluorosis risk. Fingernails were preferred instead of toenails because they are easier to collect and also because of the faster growth rate (7). Also, before starting the study, it was determined the time necessary for the fingernails to renew, assuring that the analyzed nails would be formed under the exposure or not to the F-dentifrice, in accordance with literature (12).

In this sense, although the estimated $\mathrm{F}$ intake under the exposure to diet + dentifrice $(0.086 \mathrm{mg} \mathrm{F} / \mathrm{kg} /$ day) was significantly higher than $F$ intake only from diet $(0.040 \mathrm{mg} \mathrm{F} / \mathrm{kg} /$ day $), \mathrm{F}$ concentration in fingernails was not lower when $\mathrm{F}$ dentifrice use was interrupted (Table 1). In fact, analysis of $F$ concentration in fingernails collected during the whole period of the study (Fig. 2) did not show any trend of decreasing after stopping the use of $\mathrm{F}$ dentifrice. The lack of decrease observed could be explained by an increase of $F$ intake from diet during the phase B of the study compared with phase A. However, this possibility may be discarded because $\mathrm{F}$ concentration in water was stable during the entire experimental period $(0.72 \mathrm{ppm})$ and there was no change in the diet offered to the children during the two phases. Another factor that could contribute to $\mathrm{F}$ intake from diet in phases $\mathrm{A}$ and $\mathrm{B}$ would be changes in the environmental temperature (13), but the maximum temperatures during these periods ( 26.3 and $29.2^{\circ} \mathrm{C}$, respectively) would not lead to higher liquid intake.

In this way, the findings of the present study suggest that fingernails are not a reliable marker of $\mathrm{F}$ exposure from dentifrice because nails do not have sensitivity to detect differences in the exposure dose around $0.04 \mathrm{mg} \mathrm{F} / \mathrm{kg} /$ day. Thus, it is not surprising 
that some studies have found a relationship between $\mathrm{F}$ exposure and $\mathrm{F}$ concentrations in fingernails $(8,10)$, but others not $(10,12)$. It should be emphasized that in the present study, it was estimated the dose to which the children were exposed from the dentifrice considering the soluble $\mathrm{F}$ concentration found in the dentifrice and not the one reported by the manufacturer because the dentifrice used contained calcium and part of $\mathrm{F}$ was insoluble. This method of estimation is more realistic in terms of systemic effect of $\mathrm{F}$ than the total $\mathrm{F}$ because it would represent the bioavailability of $F$ present in the dentifrice since the abrasive agent may reduce $\mathrm{F}$ absorption (16). However, the real dose may have still been lower than $0.04 \mathrm{mg} \mathrm{F} / \mathrm{kg} /$ day because the amount ingested is based on the frequency of toothbrushing reported by the mothers and also because the time of brushing and the presence of foods on stomach are not considered $(17,18)$. Therefore, it is not surprising that a dose-response effect between dose of $\mathrm{F}$ intake and fluorosis has not been found in retrospective studies (6).

The findings of the present study do not exclude the fact that fingernails can be used as a biomarker to detect $\mathrm{F}$ exposure to dentifrice when the children are exposed to a higher dose. However, the data suggesting that fingernails could be a biomarker of $\mathrm{F}$ exposure from drinking water give support to limitations of using fingernails as $\mathrm{F}$ exposure from dentifrice. Whitford et al. (7) showed that $F$ concentration in fingernails of children living in fluoridated areas with 1.6 and 2.3 ppm F was significantly higher than in children living in non-fluoridated areas $(\mathrm{p}<0.0001)$. Nevertheless, the difference between those subjected to water containing 1.6 and $2.3 \mathrm{ppm} F$ showed, by the $95 \%$ confidence interval, an overlap between the data. The dose of $\mathrm{F}$ that the children from these three area were subjected can be estimated by the amount of liquid ingested by these children per day (19), considering the maximum temperature of these areas and the mean children's weight of $21.8 \mathrm{~kg}$. The doses would be $0.00,0.04$ and $0.06 \mathrm{mg} \mathrm{F} / \mathrm{kg} /$ day for the children living respectively in areas containing no-F, 1.6 and 2.3 ppm F. Considering that these data are from Brazil where the typical foods cooked with water contribute with approximately $50 \%$ of the daily F dose to which a child is subjected (20), the total dose by liquid and solids would be $0.00,0.06$ and $0.09 \mathrm{mg} \mathrm{F} / \mathrm{kg} /$ day. Therefore, fingernail would have sensitivity to detect a difference of dose of $0.06 \mathrm{mg} \mathrm{F} /$ $\mathrm{kg} /$ day or higher, according to our findings.

In conclusion, the outcomes of the present study suggest that fingernails do not meet the parameters of sensitivity, specificity and reliability that are expected from a biomarker, suggesting that the indication of fingernails as a biomarker of $\mathrm{F}$ exposure from dentifrice may be premature and further research is needed.

\section{RESUMO}

As unhas têm sido consideradas um biomarcador para a exposição ao flúor (F), mas não há consenso se é um indicador confiável para exposição ao $\mathrm{F}$ a partir do dentifrício. Vinte e três crianças, com idade entre 1 a 3 anos, moradoras de Piracicaba (0,72 ppm F na água), Brasil, foram submetidas a duas fases de diferentes exposição ao $\mathrm{F}$ : fase $\mathrm{A}\left(1^{\mathrm{a}}\right.$ a $11^{\mathrm{a}}$ semanas), as crianças foram expostas à combinação de $\mathrm{F}$ a partir da dieta (sólidos e líquidos) e dentifrício $\left(1500 \mu \mathrm{g} \mathrm{F} / \mathrm{g}\right.$ como MFP); e na fase B (12a a $29^{\mathrm{a}}$ semanas), apenas ao $\mathrm{F}$ da dieta, uma vez que usaram dentifrício não fluoretado. As unhas das mãos foram coletadas semanalmente durante 35 semanas para determinação de F. A exposição ao F a partir da dieta e dentifrício foi também determinada. Ambas análises foram feitas com eletrodo específico para F. A exposição ao $F$ foi significativamente maior $(p<0,001)$ quando as crianças foram expostas ao $\mathrm{F}$ da dieta + dentifrício que ao $\mathrm{F}$ da dieta $(0,086$ $\pm 0,032$ e $0,040 \pm 0,009 \mathrm{mg} \mathrm{F} / \mathrm{kg}$ corpóreo/dia, respectivamente). Entretanto, a concentração de $\mathrm{F}$ nas unhas coletadas durante todo o período experimental não diminuiu após a interrupção da ingestão do $\mathrm{F}$ a partir do dentifrício. Os resultados sugerem que as unhas das mãos não são um biomarcador confiável para refletir a exposição ao $\mathrm{F}$ pelo dentifrício.

\section{ACKNOWLEDGEMENTS}

We thank Prof. Cínthia P. M. Tabchoury for the initial review of the manuscript. This study was supported by FAPESP (State of São Paulo Research Foundation, No. 99/12239-9) and CNPq (National Council for Scientific Development, No. 522679/96-0).

\section{REFERENCES}

1. Whelton HP, Ketley, CE, McSweeney F, O’Mullane DM. A review of fluorosis in the European Union: prevalence, risk factors and aesthetic issues. Community Dent Oral Epidemiol 2004;32:9-18.

2. Cury JA, Tenuta LM, Ribeiro CC, Paes Leme AF. The importance of fluoride dentifrices to the current dental caries prevalence in Brazil. Braz Dent J 2004;15:167-174.

3. Beltran-Aguilar ED, Griffin SO, Lockwood SA. Prevalence and trends in enamel fluorosis in the United States from the 1930s to the 1980s. J Am Dent Assoc 2002;133:157-165.

4. Ophaug R. Determination of fluorine in biological materials: reaction paper. Adv Dent Res 1994;8:87-91.

5. Do LG, Spencer AJ. Risk-benefit balance in the use of fluoride among young children. J Dent Res 2007;86:723-728.

6. Martins CC, Paiva SM, Lima-Arsati YB, Ramos-Jorge ML, Cury JA. Prospective study of the association between fluoride intake and dental fluorosis in permanent teeth. Caries Res 2008;42:125133.

7. Whitford GM, Sampaio FC, Arneberg P, von der Fehr FR. Fingernail fluoride: a method for monitoring fluoride exposure. Caries Res 1999;33:462-467. 
8. Rodrigues MHC, de Magalhães Bastos JR, Buzalaf MAR. Fingernails and toenails as biomarkers of subchronic exposure to fluoride from dentifrice in 2- to 3-year-old children. Caries Res 2004;38:109-114.

9. Pessan JP, Pin MLG, Martinhon CCR, da Silva SMB, Granjeiro JM, Buzalaf MAR. Analysis of fingernails and urine as biomarkers of fluoride exposure from dentifrice and varnish in 4- to 7-yearold children. Caries Res 2005;39:363-370.

10. Buzalaf MA, Pessan JP, Alves KM. Influence of growth rate and length on fluoride detection in human nails. Caries Res 2006; $40: 231-238$.

11. de Almeida BS, da Silva Cardoso VE, Buzalaf MA. Fluoride ingestion from toothpaste and diet in 1- to 3-year-old Brazilian children. Community Dent Oral Epidemiol 2007;35:53-63

12. McDonnell ST, O'Mullane D, Cronin M, MacCormac C, Kirk J Relevant factors when considering fingernail clippings as a fluoride biomarker. Community Dent Health 2004;21:19-24.

13. Lima YBO, Cury JA. Seasonal variation of fluoride intake by children in a subtropical region. Caries Res 2003;37:335-338.
14. Taves RD. Separation of fluoride by rapid diffusion using hexamethyldisiloxane. Talanta 1968;15:969-974.

15. Whitford GM. The metabolism and toxicity of fluoride. Monogr Oral Sci 1996;16:1-153.

16. Roldi CR, Cury JA. Fluoride metabolism after ingestion of dentifrice (In Portuguese). Rev Gaúcha Odontol 1986;34:425-427.

17. Ekstrand J, Spak CJ, Vogel G. Pharmacokinetics of fluoride in man and its clinical relevance. J Dent Res 1990;69:550-555.

18. Cury JA, Del Fiol FS, Tenuta LM, Rosalen PL. Low-fluoride dentifrice and gastrointestinal fluoride absorption after meals. J Dent Res 2005;84:1133-1137.

19. Galagan DJ, Vermillion JR. Determining optimum fluoride concentrations. Public Health Rep 1957;72:491-493.

20. Casarin RC, Fernandes DR, Lima-Arsati YB, Cury JA. Fluoride concentrations in typical Brazilian foods and in infant foods. Rev Saude Publica 2007;41:549-56.

Accepted April 20, 2010 